\title{
VIOLENCIA Y CRIMINALIDAD: EL CASO DEL MUNICIPIO DE CHALCO, ESTADO DE MÉXICO.
}

\author{
José Luis Cisneros ${ }^{1}$ \\ https://orcid.org/0000-0003-3957-3802
}

\section{RESUMEN}

Las condiciones actuales de violencia que se viven en México no son privativas de nuestro país, es una situación que se vive en toda la sociedad contemporánea, en algunas con mayor presencia que en otras, de suerte tal que la delincuencia ha constituido en un problema social de particular atención para las ciencias sociales. De ahí la importancia de establecer una reflexión desde la sociología, cruzando el análisis entre la importancia que adquiere el espacio social, en tanto creador de apego e identidad y su relación con el crecimiento de la criminalidad y la violencia como resultado del desapego y arraigo espacial. Particularmente en esta comunicación, apoyados en la revisión de datos oficiales (SESNSP, 2019, INEGI, 2019, INAFEDE, 2018) respeto a las condiciones y reporte de violencia delictiva que se viven en una comunidad, con características de población migrante, como es Chalco, municipio del Estado de México, y apoyados en una metodología cualitativa, exploramos las condiciones y características que se han propiciado el incremento de la violencia delictiva durante el sexenio del Enrique Peña Nieto. Los resultados de la investigación evidencian que las condiciones de vulnerabilidad en las que habitan los pobladores de este municipio han propiciado una cultura de la transgresión, desapego y miedo, impuestos por la violencia delictiva que se vive en la comunidad, y que obligo a sus habitantes, a reconfigurar el uso de sus espacios.

Palabras Claves: Espacio, apego, violencia, criminalidad, identidad.

\section{Violência e criminalidade: $O$ caso do município de Chalco, Estado de México.}

\section{RESUMO}

As condições actuais de violência vivenciadas no México, não são exclusivas do nosso país, é uma situação que é vivida em toda a sociedade contemporânea, em alguns com uma presença maior do que em outros, de tal forma que o crime tem constituído um problema social de particular atenção às ciências sociais. Daí a importância de estabelecer uma reflexão da sociologia, cruzando a análise entre a importância que o espaço social adquire, como criador de apego e identidade e sua relação com o crescimento da criminalidade e da violência como resultado de desapego e raízes espaciais. Particularmente nesta comunicação, apoiada pela revisão de dados oficiais (SESNSP, 2019, INEGI, 2019, INAFEDE, 2018), respeito pelas condições e relatos de violência criminal que são vividas em uma comunidade, com características da população migrante, Chalco, município do Estado do México, e apoiado por uma metodologia qualitativa, exploramos as condições e características que levaram ao aumento da violência criminal durante os seis anos Enrique Peña Nieto. Os resultados da pesquisa mostram que as condições de vulnerabilidade em que vivem os habitantes deste município levaram a uma cultura de transgressão, desobediência e medo, imposta pela violência criminosa que é vivida na comunidade, e que forçou os seus habitantes a reconfigurar o uso dos seus espaços.

Palavras Chaves: Espaço, apego, violência, criminalidade, identidade.

Violence and crime: The case of the municipality of Chalco, State of Mexico.

\section{ABSTRACT}

The current conditions of violence in México are not exclusive to our country, it is a situation that is experienced throughout contemporary society, in some with greater presence than in others, so that crime has been a problem social of particular attention for social science. Hence the importance of establishing a reflection from sociology, crossing the analysis between the importance acquired by the social space, as a creator of attachment and identity and its relationship with the growth of crime and violence as a result of detachment and spatial attachment. Communication in this particularly, supported by the review of official data (SESNSP, 2019, INEGI, 2019, INAFEDE, 2018) regarding the conditions and reporting of criminal violence that are lived in a community, with characteristics of a migrant population, such as Chalco, a municipality of the State of México, and supported by a methodology qualitative, we explore the conditions and characteristics that have led to the increase of criminal violence during the presidency of Enrique Peña Nieto. The results of the investigation show that the conditions of vulnerability in which the inhabitants

${ }^{1}$ UAM-Xochimilco, México. Correo electronico: cisneros.joseluis@gmail.com 
of this municipality live, have fostered a culture of transgression, detachment and fear, imposed by the criminal violence that is lived in the community, and that forced their inhabitants, to reconfigure the use of their spaces.

Keywords: Space, attachment, violence, criminality, identity.

\section{Introducción}

Estas líneas son el resultado de una investigación que se realizo en el marco de un seminario que se impartió a los alumnos del doctorado en ciencias sociales, en este seminario el propósito fue construir una reflexión desde diferentes abordajes teóricos de la relación espacio, identidad y arraigo. Sin embargo, teníamos pendiente el ejercicio empírico, que es desde donde nace la curiosidad por articular una explicación de la relación espacio y violencia delictiva.

El espacio como tal, como categoría analítica presupone comprender el funcionamiento social, las redes y las formas de organización cotidiana de una comunidad, en el marco de un contexto cultural, social y político. En este sentido pensar la complejidad de una comunidad como el municipio de Chalco, Estado de México, implica no solo observar su desarrollo, también la relación de sus pobladores junto a los fenómenos sociales que viven y padecen.

De esta manera, abordar el fenómeno de la violencia delictiva, presupone utilizar una estrategia metodológica que facilite identificar los vínculos de los sujetos con el uso y significación de los espacios, y desde esta perspectiva, la relación que tiene la violencia delicita, con la perdida del arraigo y el apego identitario, de suerte tal que a partir de esta idea, sostenemos que cuando un fenómeno como el de la delincuencia, se incrusta en los intersticios de la vida cotidiana de una comunidad, no solo rompe los lazos de socialidad, también contribuye en buena media a la perdida de apego identitario y en consecuencia construye un nuevo aprendizaje social y emocional que rompe empáticamente con la proyección del bien común.

Para demostrar nuestra idea, recorrimos el camino de la subjetividad al apoyarnos en métodos y técnicas cualitativas, frente a la interpretación de cuestionarios, desde donde se examina las implicaciones que trae consigo la delincuencia en la vida comunitaria. En este sentido la reflexión fue organizada en tres apartados, el primero contextualiza al lector, desde datos estadísticos, con el propósito de mostrar la magnitud del problema delictivo que vive el municipio de Chalco en el marco del contexto nacional. El segundo epígrafe, esta dedicado a la interpretación desde los testimonios, y las formas de concebir el espacio en voz de los pobladores y el tercer apartado analizamos los datos recogido en una encuesta que aplicamos mediante la tecina de campos semánticos.

\section{Contextualización espacial de la criminalidad}

En México el problema de la violencia delictiva y la inseguridad, al igual que en muchas ciudades del mundo, se ha convertido en uno de los principales retos de todo gobierno. La violencia criminal se ha mostrado de manera creciente desde hace tres décadas, sin poder advertir en términos reales su disminución o contención. Sus efectos han sido devastadores para la cotidianidad y socialidad, el tejido social se ha desvanecido como resultado y consecuencia de la inseguridad, que ha llegado a niveles alarmantes. Distintos han sido, los abordajes hechos desde lo académico, lo político, y lo cultural, para interpretar su crecimiento, sin embargo, muchos han coincidido que la brújula se perdió, que los valores no son hoy lo suficientemente sólidos para mantener la cohesión, en tanto que se han vencido los resortes de soporte institucional, colapsando a las instituciones; la familia, la escuela, la religión, y la perdida de creencia en la autoridad y las instituciones, han desfallecido. Muchos registros periodísticos y datos de organizaciones nacionales como internacionales han ubicado a México, en el margen del país con más ciudades violentas y peligrosas del mundo.

Muchos son los discursos que coinciden en subrayar la importancia de la prevención, así como los efectos del costo social que trae consigo las desigualdades provocadas por el modelo económico que hoy tenemos. Sin embargo, pocos son los trabajos empíricos que han intentado con éxito proponer algunas respuestas que aborden la realidad de los espacios cotidianos de la criminalidad, por una simple razón, la complejidad del problema esta en los efectos particulares de la violencia y la delincuencia en cada comunidad, en sus características y en sus condiciones. 
De ahí que nuestro objetivo, sea el análisis de la violencia delictiva y su relación con el espacio social y cultural en un sentido más amplio, desde donde situamos como eje de análisis, la relación entre el espacio y la delincuencia, en tanto que pensamos que el origen del crecimiento de la violencia delictiva tiene su base en el desmantelamiento de un tejido social fuerte, que se sostenía en tres condiciones; la primera es el apego al territorio; La segunda es la práctica de los valores y la tercera es la importancia del mantenimiento de tradiciones locales e institucionales. De ahí que cuando se pierde el sentido del reconocimiento y apego a un espacio, valorado y significado, también la identidad local, grupal e individual, se quiebra, se mutila o se diluye. En consecuencia, la violencia delictiva en una comunidad se presenta como el centro del desarraigo, y su perdida se manifiesta en la desviación social, y en el colapso de lo comunitario.

El comportamiento que ha mostrado México, en el incremento de la violencia delictiva se concentra en 50 municipios catalogados como los más peligrosos, de los 2448 que conforman la Republica. En este reducido numero de localidades, habitan uno de cada 10 jóvenes que no trabajan ni estudian, es decir 342 mil jóvenes de entre 15 y 29 años que son vulnerables y se encuentra a merced de la delincuencia organizada (Méndez, 2019).

Por ejemplo, el impacto económico según los índices de paz de 2019, de la violencia delictiva, y específicamente los delitos de alto impacto como el homicidio, secuestro y crimen organizado, en comunidades, municipios y ciudades, ha costado a los mexicanos 5 mil 161 millones de pesos en el 2018, ello implicaría una equivalencia del 24\% de PIB (IEP, 2019: 4). Sin embargo, no solo es la condición económica la causante del problema de desigualdad y violencia delictiva, sabemos bien que el fenómeno es complejo y multifactorial, en tanto que se encuentra articulado al deterioro de las condiciones de vida y desarrollo social de nuestro país.

Estas condiciones, son una de las tantas que propiciaron el incremento del $80.5 \%$ en la tasa de homicidio desde el 2015 al 2018. Tan solo en este último año, la tasa por cada 100 mil habitantes paso a 27 asesinatos, concentrados en trece entidades de la Republica Mexica, consideradas como las más violentas y conflictivas. Una condición más que tendríamos que agregar, son los niveles de percepción de inseguridad, que crecieron un $79 \%$ en el ultimo año, al afirmar la población que no sentirse segura en su entorno (ENSU, 2018: 12).

Además, en muchas de estas comunidades, habitan jóvenes en cuyo contexto social, la delincuencia es una práctica común que se define desde los grupos primarios de socialización e interacción, como resultado no solo de un sentimiento de insatisfacción, también como un sentimiento derivado por la busque de reconocimiento que se potencia por el tiempo libre y falta de acompañamiento de la familia. Estos factores sumandos a las condiciones que se viven en el país, se vuelve un caldo de cultivo y oportunidad para que la delincuencia organizada sume a sus filas a cientos de joven; por ejemplo, datos proporcionados por el Censo Nacional de Impartición de Justicia Estatal, registro 5 mil 888 adolescentes que por desgracia o fortuna, fueron procesados y sentenciados, por delitos graves; secuestro, extorsión, narcomenudeo, homicidio, violación, robo con violencia y posesión de armas de uso exclusivo del Ejercito (INEGI, 2019).

Mientras que otros niños y jóvenes más han muerto como resultado de los enfrentamientos con otros grupos de la delincuencia organizada, o bien en el momento de cometer algún ilícito. Por ejemplo, datos de la Red por los Derechos de la Infancia en México. Señalo que entre marzo de 2015 y 2019, se registraron 4,299 homicidios de menores, 285 fueron calificados como dolosos y dirigidos a menores de o a 17 años, lo que implica que son asesinados 3.2 menores por día, en nuestro país (Redim, 2019).

Como se puede apreciar, los datos estadísticos por sí mismos, no son la única respuesta para explicar la violencia delictiva, existen muchos otros datos e información que escapa al registro estadístico, como es la visión del mundo social que se forja en la cotidianidad de la colonia y el barrio. Estos espacios, son sitios propios, cargados de un gran valor cultural, son lugares donde se adquiere sentido y afirmación identitaria, que se interioriza mediante la cotidianidad. En estos espacios, la cultura callejera y la cultura de la ilegalidad, se vuelven una oportunidad para cientos de niños y jóvenes que no son acompañados por sus padres, otros más son expulsados de las 
escuelas, lo que les hace ser vulnerables y potencialmente consumidores de alguna droga en un primer paso y después actos violetos y delictivos.

La violencia delictiva desde esta perspectiva se vuelve un problema social, y se constituye en un campo de análisis, cuyas variables implican dimensiones tanto cuantitativas como cualitativas, que hace difícil su abordaje, en tanto que se encuentran implicado el miedo, la desconfianza a las autoridades y al otro, el abandono y mantenimientos del equipamiento urbano, la pobreza y las condiciones de precariedad en viven muchos habitantes de la comunidad.

Implica entonces, además de subrayar las condiciones sociales, culturales, económicas y políticas en las que se fecunda el problema de la violencia delictiva, observar el ethos de nuestras comunidades.

Según el observatorio nacional ciudadano (ONC) en su reporte de febrero de 2019, los delitos de alto impacto han experimentado un incremento que evidencia la preocupación por los niveles de la criminalidad en municipios del Estado de México como; Naucalpan, Tlalnepantla, Chalco, Cuautitlán Izcalli, Tultitlán, Tultepec, Atlacomulco, Ecatepec, Chimalhuacán, Texcoco y vale de Chalco. Son los municipios con el mayor registro de delitos de alto impacto en el país. Además, el Estado de México, es la entidad en donde los primeros cinco meses de 2018 se registraron 51 mil carpetas de investigación por robo, en sus diferentes modalidades (SESNSP, 2019).

En consecuencia, se puede afirmar que la violencia y la criminalidad, son un fenómeno frecuente y generalizado en nuestra sociedad, y que se presenta cotidianamente con diversos matices. Sus características y condiciones confrontan a los habitantes de barrios, pueblos y colonias, en una suerte de paradojas que afloran en el sentido de apego y apropiación de su espacio, lo que hace que muchos de los habitantes de estos barrios, pueblos o colonias se sienta vulnerables y junto a ello los jóvenes que las habitan, han perdido el sentido de pertenencia como resultado de la degradación que se vive en las sociedades contemporáneas.

La explicación de la creciente violencia delictiva que se vive en esos espacios, tenemos que buscarla, según consideramos, no en un registro sistemáticos de datos estadísticos, ni en una tipología de colonias o municipios más o menos peligros. Si aceptas tal cual esta idea, con ello lo que hacemos es afirmar la estigmatización de los espacios, por el contrario, consideramos que el problema que viven los habitantes de aquellas colonias donde la violencia delictiva, registra una alta incidencia, se conjuga con la desigualdad social, económica y cultural, en una suerte de relación simbólica entre cultura, identidad, apego e incremento de la criminalidad. Esta idea, nos permite afirmar que la violencia delictiva no es un fenómeno exclusivo de alguna entidad, localidad, pueblo, barrio o colonia, es más bien el resultado de la perdida de apego y disolución de pautas y significados compartidos, e interiorizados, mediante los cuales se intercambian experiencias comunes de la convivencia cotidiana que fortalecen la apropiación y la construcción de una identidad local.

Estas condiciones hacen que las personas que habitan un espacio tengan apego o rechazo por el lugar donde viven. Sin embargo, cuando las propias condiciones materiales y los recursos culturales, forjan una imagen de identidad grupal mediante el proceso de socialización, que bien tiende a fortalecer los lazos de apego, o bien coyunturalmente un desapego como resultado de la discordancia en la acciones, normas y tradiciones no compartidas ni apropiadas, que se yuxtaponen con de las diversas formas de interpretar y relacionarse con el mundo, sus conflictos y sus luchas por conseguir y disponer de aquellos recursos materiales y simbólicos que cuantitativa y cualitativamente los diferencia, frente a otros sujetos o grupos sociales, también se vuelve creador de conflicto

En este sentido la práctica común del delito como una estrategia de supervivencia, se adquiere y construye en la interacción de los grupos de jóvenes, primero como resultado de la perdida de apego, y segundo como un proceso de aprendizaje. De ahí que en estas líneas, nos proponemos primero explorar las características y condiciones del municipio y su articulación teórica a la construcción de un espacio apropiado y objetivado en las prácticas sociales, cuya particularidad se ve atravesada por el conflicto de la violencia delictiva y la fragmentación del espacio urbano que influye en la perdida del apego y el fortalecimiento de la criminalidad, como una práctica 
diferenciada, que cada vez más se hace común en la sociedad urbana moderna, y en donde los jóvenes buscan constantemente, por cualquier medio, satisfacer el consumo de alcohol, drogas y obtener un prestigio efímero mediante la práctica de la violencia delictiva.

De ahí que para lograr una explicación entre la condiciones contextuales de une espacio y sus habitantes, metodológicamente nos hemos apoyado para el logro de este planteamiento en el relato de vida, particularmente utilizando entrevistas focalizadas, en la medida que se considera una herramienta que facilita y orientar nuestra observación hacia la vivencia singular de lo social, así como para recuperar del sujeto entrevistado, el sentido y la práctica de lo cotidiano. Las entrevistas, se dirigieron a persona reconocida por los vecinos, también algunas otras las recuperamos de jóvenes internos en el Centro penitenciario de Chalco (por privacidad de los entrevistados se usaron referentes y nombres genéricos). Sobretodo, porque consideramos que, desde esta perspectiva, la subjetividad del espacio social se muestra en la singularidad de las experiencias vividas, y como expresión colectiva de la objetivación del espacio valorado, significado y apropiado.

Como se puede apreciar no solo se trata de dar cuenta de un comportamiento particular, para interpretarlo no como fragmento de la historia individual, sino como una dimensión social que facilite explicar la relación del comportamiento delictivo y las formas de reproducción de las prácticas sociales de violencia. De ahí, que al pretende estudiar la relación entre el espacio y la violencia delictiva, se considere que el trabajo de campo también debe nutrirse de la mayor participación posible, con los integrantes de la comunidad en estudio, por tal razón se diseño un instrumento que aplicamos a 603 personas, con el objetivo de conocer la representación que tienen de su espacio y las dimensiones emotivas y valorativas que atribuyen cotidianamente a su espacio.

\section{El ejemplo aplicado}

Chalco es un municipio del Estado de México, que tiene como cabecera la ciudad de Chalco, y se encuentra delimitado por los municipios Ixtapaluca, Cocotitlán, Temamatla, Tenango del Aire, Tlalmanalco, Juchitepec, Valle de Chalco Solidaridad y el Distrito Federal (INAFED, 2018). Es una ciudad media que se ha convertido en una zona importante de la región centro, de la entidad como resultado de las actividades comerciales, industriales y de servicios, como lo es el tradicional tianguis de los viernes, en donde se despliegan una gran actividad comercial de la región. El Municipio se compone de cuatro barrios, diecisiete colonias y trece pueblos.

El municipio desde finales de la década de los setenta fue receptor de vertiginosos asentamientos en su periferia, de familias provenientes de los estados del centro y sur del país. Las familias, llegaron con la esperanza de tener un lugar donde vivir, y formar un patrimonio para sus hijos, lo que sin duda marco la condición y practica social y cultural la zona.

“Tengo 52 años, no trabajo más que en mi casa... (se ríe). Aquí vivo con mi esposo y seis hijos. Tenemos 28 años viviendo en la colonia. Llegamos aquí porque a mi esposo, un compadre le vendió este terrenito, por eso nos venimos hasta acá... cuando llegamos no estaba el drenaje, ni el agua, apenas tenemos como 10 años que nos pusieron los servicios.

Cuando llegamos, sí había robos, pero no eran tanto, uno que otro. ... Mmmm, no pues hoy a cada rato se entera uno, con la vecina, la comadre y la señora de la tienda, o en las tortillas, en el tianguis, o luego me encuentro a las vecinas y me cuenta cosas espantosas, me da mucho miedo, ya le dije a mi viejo que se cuide muchos, a mis hijos, me preocupan. Uno de ellos que luego llega tarde por su trabajo, y el pobre se viene caminando desde la carretera" (Señora Teresa, 2018a).

La dinámica social en la que está sumergida la vida cotidiana del municipio se encuentra determinada por una constante de violencia delictiva, que ha experimentado desde la década de los 90. Sin embargo, en los últimos años, la invasión de predios, la falta de servicios y la constante reventa de terrenos, se sumo a fenómenos de linchamientos, y a la aparición de bandas de jóvenes que delinquen, jóvenes adictos que deambulan por las calles, así como cuerpos que amanecen 
tirados en las esquinas o en los terrenos baldíos, secuestro, extorciones, ejecuciones, violaciones, robos de vehículos, a casa habitación y a transeúntes.

Tengo 51 años, estoy casada, tengo dos hijos. Vivo en la colonia desde hace 24 años. Vine a esta colonia porque pude juntar un dinero y comprar mi casa. La colonia era muy tranquila, todos te saludaban los vecinos eran muy tranquilos, otros no tanto. Hoy procuro no salir, ni convivir mucho con ellos, algunos son personas muy desagradables. Antes podías salir tranquilamente a caminar, aunque no había tantas casas, y era más fácil platicar con la gente, ahora ya no es tan fácil, muchas calles no están alumbradas. En la colonia asaltan mucho, también han matado a unas personas, hoy es diferente. Hace unos años escuchabas de las bandas de los vagos, que se peleaban y esas cosas, pero ahora están los narcos; que la familia, que las zetas, que del golfo. Uno escucha muchas cosas, ... en las noches, ves a muchos chavos, que se drogan y que venden.

Lo más común en la colonia son los asaltos, todos sabemos por las vecinas que nos platican cuando las asaltan, o alguno de sus familiares, y no solo de noche sino en el día (Señora Gudelia, 2018a).

Desde la llegada a la presidencia de la Republica de Felipe Calderón, el municipio sufrió un cambio radical, "La Familia Michoacana (FM) echó raíces en Valle de Chalco al tomar el control de la distribución de drogas, las extorsiones a comerciantes, y el cobro de piso a establecimientos mercantiles, siempre bajo el beneplácito y apoyo de la policía municipal y estatal" (Vanguardia, 2012).

De esta manera los municipios de Ixtapaluca, Chalco y Valle de Chalco; se convirtieron en lugares inseguros, donde el robo a comercios y transeúntes se ha vuelto uno de los mayores temores de la localidad, así como las continuas ejecuciones por la disputa del control de la venta de droga.

Los delitos no son denunciados, como resultado de su frecuencia y falta de respuesta por parte de las autoridades locales, estatales y nacionales, han alcanzado niveles insospechados de transferencia y asimilación, como resultado del miedo, y como mecanismo de vinculación con patrones de comportamiento cotidiano que se articular a una práctica contemplativa, que por un lado, estabiliza y neutraliza el miedo y la violencia delictiva, en una suerte de tolerancia y por el otro forma parte de un aprendizaje cotidiano, en que la violencia delictiva es normalizada.

Tengo 32 años viviendo aquí, y 23 años con mi tienda. Solo tenemos un hijo. Llegamos a la colonia, porque en ese entonces yo trabajaba en una gasera, que esta aquí, por San Vicente.

Lo desagradable de mi calle y de la colonia es el polvo, siempre tenemos tierra, muchas calles no esta pavimentadas o llenas de hoyos. Además, tenemos mucha gente nueva, ... no me gustan, son groseras. Llego mucha gente del centro de la ciudad (CDMX) Muchos son muy broncudos, marihuanos, borrachos, de todos tenemos en la colonia, eso no me gusta.

Nunca nos han asaltado, pero veo aquí afuera de la tienda como han agarrado a la gente que luego pasa, son los chavos que anda drogados o borrachos. No me meto, siempre están por aquí afuera de la tienda, luego me piden prestado que una caguama o un refresco, una torta o unas papas, y mejor se los presto, nunca me pagan, pero prefiero no tener problemas. Además, nos conocen bien, y no se meten con nosotros.

En la tienda escucho muchas cosas, algunos dicen, unos que viven en la otra cuadra, que luego vienen en unos carrasos, son secuestradores, pues no se si es verdad o no, yo mejor los trato muy bien (Señor Alfredo, 2018a)

En este contexto los jóvenes se vuelven uno de los actores fundamentales de la realidad local, su condición esta marcada estructuralmente por el grupo de pertenecía, así como por las carencias que vive la familia, por la pobreza, la desigualdad, el desempleo, la marginación y la exclusión. Condiciones que se vuelven un caldo de cultivo para entender su participación en conductas 
delictivas, lo que hace que este fenómeno sea complejo en tanto que la violencia delictiva se encuentra articulada de manera indisoluble a determinadas condiciones del contexto social en el que se encuentra inmersos estos jóvenes.

Muchos de los problemas que han surgido como efecto de esta violencia delictiva, por un lado, como lo hemos mencionado, obedecen a factores nacionales y la expansión de grupos de narcotraficantes que luchas por expandir sus mercados y controlar zonas de distribución y comercio de drogas. Esta expansión facilito la diversificación de delitos, algunos de alto impacto, como el secuestro, otros de menor impacto social, pero de mayor afectación en la vida cotidiana de la comunidad.

Esta condición, facilito la incorporación de muchos jóvenes al mercado de la ilegalidad, otros más se hundieron en la dependencia de las drogas, lo que implica entonces reconocer la presencia de dos factores interdependientes; uno la conducta de los jóvenes; el otro, la reacción de la comunidad cuyo impacto trae consigo el quiebre del tejido social. Son jóvenes con muchas dificultades para socializar, y con problemas de conducta desde temprana edad, tanto en la familia como en la escuela, con limitaciones económicas y sin ocupación alguna.

"Desde chavo comencé a robar, primero le sacaba a mi jefa dinero, luego a mis tías y así, después me enganché ¿entiendas verdad? Las drogas son cabronas, no se puede, por más que quieras, ... después esperaba a los que veía más pendejos y les pedía que me hicieran un paro, otros se ponían al pedo, y les pasaba bascula, ... después ya empezó el rollo, no podía controlarme cuando robaba, les quitaba todo..." "2

Muchos de estos jóvenes, han perdido su identidad como estudiantes y como trabajadores, son jóvenes pobres, desocupados y casi indigentes, cuya socialización esta condicionada por la desocupación, el estigma y la adicción. Su socialización esta marcada por el impulso de la transgresión como una forma de vida ligada a la violencia delictiva. Otros se han incorporado a la economía informal, tanto legal como ilegal, pero, aun así, sus condiciones de remuneración son precarias, algunos se dedican a la venta de droga, otros al robo de vehículos y de autopartes, al robo a transeúntes, robo al transporte, entre otros delitos. Estas actividades son constitutivas de su cotidianidad, y forman parte de una estrategia alternativa para obtener recursos, frente a las escases o negativa de un empleo.

De ahí que las expresiones de violencia delictiva formen parte; por un lado, de la condición en las que se crean estas colonias y por el otro, de una suerte de estrategia de sobrevivencia, para muchos jóvenes excluidos y marginados de instituciones de socialización como la familia y la escuela, de ahí que la violencia con la que actúan bien puede entenderse como el reflejo del sistema social en el que viven.

"Termine la secundaria mal, pero la termine, desde que me acuerdo, en la primaria siempre me aburría, no me gustaba, las maestras siempre me castigaban, y le decía a mi mama que no me portaba bien, ... en quinto año, él bolas estaba en mi salo, un dime me dijo que le prestara para compra algo, nunca me daban dinero. Me dijo, que la maestra dejaba su bolsa en el estante, ... me dio miedo, pero fue chido, compramos cosas y hasta regalamos. Luego en la secundaria, fui un desmadre, mis jefes me dejaban hace lo que quisiera, me juntaba con unos valedores, y nos saltábamos las clases, luego no íbamos, ahí empecé, primero fue una tienda, luego un camión, luego un Oxxo, y así, hasta que conocí a cuates mas pesados. Simpe le daba a mi jefecita fierros, nunca me dijo nada, ... a mi jefe lo mataron en una cantina y mi jefa murió hace 5 años, mis carnales, andan en otra cosa, ... la lacra soy yo. ${ }^{3}$

El modelo de desarrollo metropolitano que vivió el Estado de México, no solo genero la demanda de servicios, también transformo estos espacios en grandes comunidades dormitorio, los cuales

2 Joven de 26 años, interno en el Penal de Chalco Estado de Mexico, con una sentecia de 6 años por robo con violencia.

${ }_{3}^{3}$ Joven de 19 años, interno en el Penal de Chalco, Estado de México. Con una sentencia de 17 años cuatro meses, por robo y homicidio calificado. 
progresivamente se convirtieron en comunidades altamente complejas por dos centralidades que consideramos fundamentales; la primera, tiene que ver con la concentración de migrantes, arropados por una política de protección social insuficiente que intensifico una economía sumergida en la ilegalidad, que fomento la invasión y ocupación predios de manera irregular, facilitando así la ampliación de estrategias marginales de vida y un espacio propicio para el desarrollo de la violencia delictiva. La segunda, obedece a la excesiva movilidad de sus habitantes, cuya tendencia más relevante, se concentro en la desigualdad, la pobreza y la exclusión de sus pobladores, particularmente en las nuevas generaciones de sus ocupantes de donde salieron las filas de jóvenes delincuentes que hoy se encuentran, algunos en prisión otros por las calles del municipio. Jóvenes con escasos recursos económicos, expulsados de las escuelas sin posibilidades un trabajo y sumidos en la pobreza, cuya fragilidad identitaria apenas se sostiene en un espacio que difícilmente reconocen como algo propio.

Son digámoslo así, desplazados de áreas o zonas afectadas por el desempleo, la desigualdad social y la reestructuración económica, además de otros problemas sociales que los marca con un malestar social altamente significativo, que produce enojo, rencor y un sentimiento de orfandad, que produce en algunos jóvenes una suerte de disolución de valores y normas sociales de apego y construcción identitaria familiar y grupal.

Estas condiciones, y su evolución se convirtieron en el precursor de la violencia delictiva y con ellas, surgen nuevas formas de estructuración, ocupación y significación cultura del espacio, las cuales poco a poco fueron modificando la funcionalidad de las colonias, al polarizarse los lugares, un tanto por la concentran de actividades delictivas, otro tanto por las condiciones de desarrollo económico.

"Antes caminábamos desde la autopista hasta la casa, no hoy no se puede, esta muy oscuro y siempre andan por ahí, esos muchachos drogados, y luego mire, toda esa parte desde el puente de allá, hasta la entrada de la colonia, lleno de bares y hoteles, ... no esta bien feo, luego andan los de periódico, diciendo que mataron a uno o que encontraron a una muchacha, ... padre santísimo, me da mucho miedo. Ya no puede uno salir por la noche, ni camina lejos, mira a tres calles esta la panadería, yo mejor compro mi pan temprano, después ya no salgo. A mi yerno, lo asaltaron, aquí lueguito, cerca del zaguán, le quitaron su teléfono, su saco y su reloj, pero gracias a dios no le paso nada, solo el susto y sus cositas ..." (Señora Teresa, 2018b)

Las condiciones de la comunidad son de una evidente marginación y fragilidad, cuya tendencia se muestra en el declive de sus lazos de socialidad, como resultado de la concentración de actividades delictivas y al mismo tiempo la generación de una forma de vida determinada estructuralmente por la exclusión social, el desapego y la falta de comunidad identitaria.

Si todos nos uniéramos para agarrar a estos rateros, $\mathrm{mmm}$ no andarían por aquí, pero no se puede no todos los vecinos nos unimos, unos tienen miedo, otros porque son sus propios muchachos que anda de vagos, imagínese. El hijo de la señora que vende las verduras, ... pobre señora, su hijo este perdido en la droga, pobre muchacho, luego ni reconoce a nadie y anda asaltando, luego ya le dicen, Elenita, su hijo asalto a tal o a cuál, imagines pobre muchacho. La colonia ha crecido mucho, mucha gente ha llegado, ya no nos conocemos, por eso no nos unimos, no podemos protegenos, no convivimos. Mier muchos ya ni van a misa, ahí uno siempre conoce a mucha gente de la colonia, ahora ya ni van, somos siempre los mismo que estamos ahí.

No nos cuidamos, hace como medio año, en la esquina, ...vio esa casa bonita de dos pisos, ... si esa, pues la vecina de enfrente vio como uno sacaban las cosas de la casa, y cree usted que fue para llama a la policía, pues no la llamo, que mala persona. Hubiera hecho algo, pero no somos unidos, mucha gente sale temprano 
y llega tarde, luego ni cuenta te das quien entra o sale de una casa (Señora Teresa, 2018c).

Lefebvre, (1973: 19) ya insistía en subrayar que todo proceso de urbanización genera segregación social en los más desafortunados, aún cuando algunos, conservan una fuerte posición de arraigo a su ciudad de origen, pero el hecho real es que desembocan en un estado de marginalidad, que condiciona el papel del tejido urbano como un elemento sustancial de la dinámica diaria.

La condición de periferia, en la que se ubica el municipio, permite entenderla como una constelación de núcleos polarizados por puntos específicos de problemáticas sociales, que progresivamente han transformado y desmantelado la cohesión social del espacio, como resultado de la creciente actividad delictiva que amenaza no sólo a sus habitantes, sino que con ello marca un acelerado declive en la vida urbana de la localidad.

El problema es que los vecinos no somos unidos, muchas veces por miedo, o por represalias, ... uno mejor se queda callado, a veces uno ve cuando están asaltando a las personas o algún vecino, o haciendo cualquier cosa, y yo mejor no me meto, no quiero tener problemas. Creó que eso no debería ser, porque somos vecinos y todos deberíamos estar unidos, pero la verdad es que todos tenemos miedo. Por eso, nosotros si no tenemos a que salir a la calle, mejor no salimos y mas si es de noche.

Hace tiempo, un señor de por acá atrás, vio como estaban robando el carro de un vecino de su calle, y agarro a uno de los rateros, después ... a la semana, mataron al señor, no se sabe si fueron ellos mismos, o no se quien, pero da miedo, por eso nadie se mente, ... Cuando un habla a la policía no viene y cuando llega, ya es muy tarde (Señora Gudelia, 2018b).

Las condiciones de desarrollo, cohesión, convivencia y apego son determinantes para la conformación de los ciudadanos, los hijos, los alumnos; por tal razón el papel fundamental del espacio, no sólo es brindar un soporte de contención, es también fortalecer la socialidad desde diversas actividades y grupos institucionales; familia, escuela, religión, gobierno, y convertirse en un muro de contención contra la desestructuración del tejido social, contra el desmoronamiento silencioso de las redes de pertenecía, que dan fortaleza, apego y aprecio por un lugar, una colonia, un barrio. Sin embargo, como se puede advertir, en este municipio la vida cotidiana, común y ordinaria de los pobladores se ha transformado, como resultado del impulso impuesto por la violencia delictiva.

Nuestro problema es la inseguridad, uno siempre tiene miedo, ... cuando salgo a mi trabajo o cuando voy al mercado, me cuido mucho porque pienso que me pueden asaltan y de aquí a que llegue la policía, mmmm pues y paso todo. Es muy fácil para el ratero no hay nada que lo detenga. Nunca me voy por el canal, aunque ahora ya pusieron unas cámaras, no sirven de nada, de todas maneras, ves a los drogadictos y chamacos por todas partes, luego le quitan a uno sus cosas. (Sra. Gudelia, 2018b)

Necesitamos andar seguros en la calle, la verdad luego es peligroso, faltan muchos focos en los postes, y luego asaltan a la gente que pasa por aquí, yo seguido me entero, ... porque viene corriendo y se meten aquí a la tienda. Mire en la otra esquina es la parada del camino y los peseros que llegan de Zaragoza, mucha gente sube y baja por aquí, entonces uno se da cuenta (Señor Alfredo, 2018b).

La dinámica impuesta por la inseguridad propicia un ambiente de desintegración y crisis familiar, particularmente en las nuevas generaciones, las cuales ha sido absorbidas por los grupos del crimen organizado, otros más son empujados a tomar el camino de delito, como alternativa de sobrevivencia. (Castells, 2014; 78).

Cuando está en la secu, me fui a vivir con mi abuela. No me gusta estar en mi casa, mis jefes siempre andaban en broncas, ... un rollo con mis jefes. Mi abuela siempre me decía que obedeciera, que estudiara para que no fuera como mi jefe, luego mi 
jefe se fue de la casa y mi mama, me llevo con ella, ... para vivir a la familia feliz, pero no me gusto, llega con sus novios y eso me cagaba, ... Mi abue murió y me calo bien gacho, ... después me fue con unos compas, con ello comenzó todo, empecé a conocer buenos lugares, a tener baros, me gusto, la verdad si pudiera volviera a buscar a mis compas. Me enseñaron a trabajar, primeo abrir cerraduras, luego a tirar y así,... hasta que me agarraron ${ }^{4}$

La apropiación del espacio es determinante para el desarrollo del sujeto, por ello Borja explica que "las relaciones entre los habitantes, el poder y el sentido de pertenencia se materializan y se expresan en las calles, en las plazas, los parques, los lugares de encuentro ciudadano, en los monumentos. En esta relación uno puede entender el espacio urbano como sistema de redes o de conjunto de elementos [...] que permiten el apego, la apropiación y el encuentro, elementos todos, que dan sentido, y estética al espacio físico, es pues la expresión colectiva y de la diversidad social y cultural componentes de apego y de formación de identidad" (Borja, 2009: 28-29)

Es decir que el espacio público es expresión de cultura urbana y de una ciudadanía que la habita, la significa y se identifica con ella mediante la narración de sus acontecimientos, de lo que se vive, se apropia y se sufre.

Entonces comprender la problemática de inseguridad, mediante los rasgos de la cotidianidad, sin duda muestra la dinámica, práctica y significado que se le atribuye al espacio vivido. Cada una de estas condiciones o rasgos, forman parte de una estructura que aglutina la calle y dibuja la estructura imaginaria de su ritmo, sus desplazamientos y sus relaciones. Son por decirlo así, la parte constituyente de una semántica que se instala en la dimensión de un lenguaje plural de historias vividas, difundidas y estratificás por los habitantes de la localidad. Donde los miedos se encuentran sumergidos, en las condiciones estructurales culturales y simbólicos de inseguridad.

En esta condición, la emotividad de la estigmatización, la condición de marginalidad, la falta de oportunidades de un empleo bien remunerado, el acceso a servicios de salud, educación y servicios de vigilancia y la precariedad que envuelve a los pobladores, engendrada, respuesta de agresión y violencia personal, en muchos jóvenes y habitantes del municipio (Borja, 2000).

\section{Las improntas de lo comunitario}

El malestar que se vive en el municipio de Chalco, esta relacionado de manea especifica con una demanda eficaz de seguridad, para contener la ola de violencia delictiva, además nos queda claro que dicha demanda es un reflejo de la condición espacial y social de la arquitectura simbólica que define a sus colonias y a sus habitantes.

En consecuencia, el poner atención a los vértices que objetivan el espacio de la comunidad, nos aproxima a observar de manera más delimitada, los vínculos y relación de los pobladores con sus espacios, trayecto o lugares de socialidad. De manera tal, que son visibles, ciertos comportamientos en el espacio social, cuyo imperativo se traducen en la demanda, de protección, y construcción de un imaginario del miedo, como la expresión de algo que puede ocurrir. Es algo así, como la construcción de una tipología de los conflictos y los riesgos generados por los comportamientos de los habitantes, y que se hacen evidentes en lo que perciben o representan algunas actividades cotidianas, por ejemplo, el trasporte público, que es una de las principales formas en la que los habitantes del municipio se mueven. El transporte articula espacios; el trabajo, la casa, los centros de diversiones, la escuela, etc., se trata de una práctica cotidiana a la que pocos pueden renunciar, en tanto que forma parte importante de la vida colectiva.

Cuando se pregunta a los pobladores la opinión que tienen del transporte público, mostraron una imagen de peligro y sentimiento de miedo, construida colectivamente y atada a espacios comunes. El miedo a la delincuencia, el cual, si bien se convierte en un factor de cohesión social, también expresa un fuerte sentimiento de indefensión

\footnotetext{
4 Joven de 27 años, interno en el Penal de Chalco ,Estado de Mexico. Con una sentencia de 20 años siete meses, por homicidio calificado.
} 
No bueno no, ... no me gusta ese rollo de que te digan delincuente, yo no soy delincuente, más bien creo que todos tenemos buenos y malos ratos, y pues yo ahora tengo un mal rato, ... no me acuerdo bien de que paso, andábamos cotorreando y después cuando desperté ya estaba bien prensado. ${ }^{5}$

La sensación de indefensión se encuentra generalizada, primero porque existe un incremento real de la violencia delictiva en las calles, pero también la percepción que se tiene de la inseguridad, en buena medida es inducida por los medios de comunicación que alimentan un imaginario cuya dimensión cultural permanece oculta en la mirada de los habitantes de la comunidad. Así, la desconfianza induce no solo a mantener distancia física uno del otro, sino a romper lazos de comunicación y a reconfigurar los espacios culturales de socialización.

Esta sensación, caracteriza la manera de ver la calle, bajo un sentido de desfiguración social, en el que se ve no solo la ruptura del tejido social, también revela las condiciones de desigualdad y las conductas no deseadas por la comunidad. Es una imagen, que ayuda a explicar los efectos que trae consigo la violencia delictiva en la perdida de apego y desarraigo.

De esta manera cuando preguntamos que significado tenia la calle para los encuestados, la respuesta mostro una relación entre cercanía y lejanía, así como la percepción que ellos construían mediante la palabra de su propia realidad.

La calle es importante en tanto que se vuelve una prolongación de la casa, es digamos así, la entrada y la salida de los espacios apropiados y valorados afectivamente, además. La calle guarda una estrecha relación entre el espacio y el tiempo, en tanto que mide los desplazamientos y distingue los limites entre lo publico y lo privado. Se trata de un espacio abierto de progresivo aprendizaje. La calle tiene una doble función, por un lado, es un espacio de uso publico, por el otro abre la posibilidad de algunos peligros, que reflejan la condición de vulnerabilidad que se vive, como resultado de la creciente violencia delictiva, la cual se suma a la exigencia de una demanda de seguridad, que se encuentra fuertemente asociado a las condiciones de precariedad que se viven en el municipio.

De ahí que, para algunos habitantes del municipio, considerar la privatización de los espacios público, implica poner un limite entre el afuera y el adentro, entre lo individual y lo grupal, implica la trastocación del habitad, al romper la relación del si mismo, con el mundo social y con la historia personal del sujeto.

Cuando los pobladores de Chalco construyen la idea de las calles cerradas como un lugar de refugio y resguardado del peligro y la inseguridad, piensan en el espacio defendible, en imagen de una fortaleza cuyas entradas deben ser custodiadas ante los extraños, los diferentes y los sospechoso, es por decirlo así, la idea de un repliegue del territorio, en tanto que la privatizarse el espacio público, presupone su fragmentación, como resultado de la experiencia marcadas por la ruptura de la proximidad y la convivencia, que ante el miedo se borra la homogeneidad de los comportamientos convencionales, para dar lugar a la heterogeneidad de conductas estereotipadas como transgresoras e incompatibles con la ética del cuerpo social colectivo.

Los pobladores siempre estructuran sus espacios, espacios fijos y espacios móviles, mediante ellos establecen formas de interacción y control. En estos espacios, el comportamiento forma parte de un marco básico de las actividades de los sujetos y del colectivo, son expresiones constitutivas de una organización, que esencialmente muestran una imagen del arraigo.

Cuando estas formas de organización espacial se modifican por algunos acontecimientos ajenos a la intención de la grupalidad, inmediatamente aparece una ruptura en los hábitos cotidianos que inducen a la perdida del vinculo personal con el colectivo, y modifica la compartimentación que habitualmente otorgaba consistencia y fortaleza identitaria a los pobladores.

Coyunturalmente, dos comportamientos se encuentran íntimamente ligados al sentimiento de inseguridad y miedo, son comportamientos que objetivamente se asocian al deterior estructural y

${ }^{5}$ Joven de 21 años, interno en el Penal de Chalco ,Estado de Mexico. Con una sentencia de 4años cuatro meses, por robo a transporte. 
cultural que vive la población del municipio, como resultado de las experiencias limite que viven cotidianamente los pobladores.

Se trata de una construcción imaginaria que evoca un tiempo de vulnerabilidad y abandono en la esfera de lo político, como resultado de las trasformaciones del espacio urbano, desde donde destaca el miedo, el miedo al otro, al diferente, al ajeno, al abyecto y al subversivo.

Son imágenes emotivas y profundas que muestran heridas de incertidumbre, discriminación y sospecha de todo y de todos. Además, en el fondo, hacen referencia oculta a la complejidad social de los comportamientos que escapan a la articulación de orden social y simbólico, y que giran entorno al miedo y la posibilidad de sufrir un asalto o un asesinato en la calle.

En este sentido la estigmatización y los juicios construidos por el crecimiento del consumo de drogas en la comunidad, desencadenan temores ligados al deterior del tejido social y a la construcción de nuevas subjetividades en torno a las sospechas de escenarios de incertidumbre, que quiebran las intuiciones que tradicionalmente son reconocidas como soporte de apego, mediante un discurso moralizante lo asocian a sujetos culpables que provocan conflictos y se vuelve una amenaza que quebranta la confianza de las instituciones sociales que dan sentido comunitario.

En consecuencia, cuando la adhesión al espacio, las costumbres y la reciprocidad de la convivencia se vulneran, dejan un amplio margen para el incremento de la violencia delictiva y del consumo de drogas, el cual contribuye en buena medida al incremento de la criminalidad. Primero porque el nuevo patrón de consumo y la diversificación de las drogas, ha propiciado un uso intenso y generalizo en algunos sectores de la comunidad. Segundo, porque el consumo de las drogas, creo una compleja estructura de actividades destinadas a la venta y distribución en las colonias del municipio que las automarginó, al reconstituir los itinerarios que habitualmente recorrían sus habitantes.

El desorden en el espacio urbano en algunos casos trasmite a la comunidad una idea de desinterés, aislamientos y desvanecimiento de los códigos de convivencia, que no solo produce desapego y perdida de identidad, también motiva el desacato el uso esporádico de la justicia en sus propias manos (Egea, 2008:245). En otros casos hace que sus pobladores se refugien en si mismo, que se aíslen y se sientan ajenos a la idealización de la vida barrial o comunitaria.

Esta última visión se construye sobre constelaciones de miedo que remiten a la formación de un núcleo sostenido por la percepción de un sentido amplio de la inseguridad que implica condiciones laborales, educativas y de salud. Es un núcleo donde la incertidumbre de un futuro rompe con el pasado real y el futuro mítico.

La construcción simbólica de este núcleo no es un ejercicio neutral, es más bien la expresión individual que uniforma comportamientos que motivan la transformación del espacio y la ida comunitaria. Es la imagen de una representación inusual que muestra la coexistencia entre el aislamiento y los múltiples miedos expresados por operaciones metonímicas, donde los temores evidencian no solo la condición de violencia delictiva que se vive en el municipio de Chalco.

Muestra también un campo simbólico del universo espacial, en tanto fundador de orden y de relaciones jerárquicas con lugares de socialidad que son señalados por fragmentos lingüísticos, los cuales representan una distancia social respecto a una demanda de una protección efectiva, como resultado del deterioro causada por el crecimiento de la violencia delictiva, el vandalismo y la drogadicción que ha vivido en la ultima década el municipio.

La imagen muestra los puntos centrales de una preocupación, o más bien es el esbozo de trazos o actitudes que han roto la convivencia y alterado el sistema de comunicación de la localidad, es una muestra simbólica de las afectividades que han quebrado la inserción y reconocimiento de muchos pobladores al espacio común.

En este sentido los espacios tradicionales de circulación de la socialidad se encuentran puestos al limite, por la ausencia de apego a la familia, la escuela y al lugar de residencia, por lo que las condiciones para cometer algún acto delictivo aumentan, en tanto que se diluye el auto control y 
se socializan los jóvenes con normas y práctica delictivas que, al ser interiorizadas, se normaliza la violencia delictiva.

De ahí que el reacomodo de los principios socializadores, que experimenta la comunidad, no solo este inscrito en la práctica cotidiana del deterioro social, económico y político, se inscribe también, en el miedo, la desconfianza, la sospecha y la estigmatización al otro y en las condiciones de salud emocional tanto individual como colectiva.

También puede observarse en el conflicto entre padres e hijos, entre vecinos entre gobernante y gobernado, es decir que en este reacomodo de normar y valores de socialización, la empatía se ausento y cuando no esta ultima no esta presente, las consecuencias en las conductas son devastadoras, por que en ellas el miedo no tiene cabida y el sentido de autoridad queda anulado. Entonces matar, violar, trasgredir, anular o eliminar, se inhiben como conductas que supone un daño al otro.

\section{A manera de epílogo}

Antes de intentar exponer una reflexión final, quisiéramos subrayar que todo espacio es constitutivo de apego e identidad, sin embargo, existen algunas condiciones tanto individuales como colectivas que producen abandono, ruptura o desapego, y en algunos casos las mismas prácticas sociales, ponen en quiebra los valores y las normas de identificación que funcionan como imperativos morales de cohesión para toda comunidad.

Sin embargo, la propia cultura de la localidad impone y modifica los valores y junto con ello, el sistema de relaciones sociales y espaciales al dividir, seleccionar y jerárquicamente los espacios, en una suerte de topografía del terror y el miedo que produce ruptura en la pertenencia, y sella con marcas indelebles el imaginario colectivo, de aquellos espacios identificados como puntos de conflicto, en los cuales se rompe la proximidad y la socialidad. Es pues una suerte de proyección de los conflictos que no solo dañan materialmente también crea de manera simultánea, una condición psicológica que marcala historia personal y colectiva de la comunidad.

En consecuencia, se puede afirmar que si bien no existe una sola perspectiva que nos permita abordar la complejidad del fenómeno delictivo y su estrecha relación con el espacio vivido, hemos querido mostrar con nuestro trabajo de investigación, que la violencia delictiva no solo es una conducta que lacera la dinámica del grupo primario, por el contrario, consideramos que hemos podido mostrar como este tipo de violencia, impone patrones de reconfiguración del uso del espacio colectivo.

Además, cuando la violencia delictiva adquiere una mayor escala en la comunidad, produce una marcada diversificación del uso de los espacios, conforme se distribuyen las acciones de la delincuencia y con ello una clara diferenciación del tipo de victima.

En el caso de nuestra investigación, el municipio de Chalco, se consolido como una comunidad con variadas significaciones sociales, desde la década de los años setenta, donde la delincuencia siempre formo parte del paisaje migratorio y los asentamientos irregulares, sin embargo, en la ultima década es cuando mostro un evidente aumento, que emergió como resultado de la expansión del crimen organizado, la corrupción y el abandono gubernamental.

De este modo el sentimiento de inseguridad y el temor de las acciones realizadas por jóvenes delincuentes, se expreso en una nueva forma de organización de la vida cotidiana de los habitantes, y junto a ello se profundizo la desconfianza y la estigmatización, como resultado de la distribución espacial de la delincuencia. De ahí que el problema de violencia delictiva que vive el municipio de Chalco, no solo se convirtió en uno de los principales factores que ha propiciado la pérdida de apego territorial, junto con otras variables o generalizadas como es el problema delictivo que remodelo la relación espacio tiempo e individualizo la relación social.

\section{Referencias Bibliográficas}

Alfredo (2018a) Entrevista personal, 13 de abril. Chalco. México.

Alfredo (2018b) Entrevista personal, 19 de mayo. Chalco. México. 
Borja, Jordi. Muxí Zaida (2009) El espacio público, ciudad y ciudadanía. Electra, España. Castells Manuel. (2004) La cuestión urbana. Siglo Veintiuno. México.

Egea Jiménez Carme. (2008) Vulnerabilidad del tejido social de los barrios desfavorecidos de Andalucía. Análisis y potencialidades. Centro de estudios Andaluces. Consejería de la Presidencia. España.

ENSU. (2018) Encuesta Nacional de Seguridad Pública Urbana. INEGI. México. Extraído de: https://www.inegi.org.mx/programas/ensu/ consulta: 06/05/2019.

Gudelia (2018a) Entrevista personal, 7 de abril. Chalco. México.

Gudelia (2018b) Entrevista personal, 16 de mayo. Chalco. México.

IEP. (2019) Índice de Paz México. Identificar y medir los factores que impulsan la paz. IEP. México. Extraído de: http://visionofhumanity.org/app/uploads/2019/04/MPI-ESP2019-Reportweb.pdf consulta: 13/02/2019.

INAFEDE. (2018) Enciclopedia de los Municipios y Delegaciones de México. Extraído de: http://www.inafed.gob.mx/work/enciclopedia/EMM15mexico/municipios/15025a.ht ml consulta: 11/03/2018.

INEGI. (2019) Censo Nacional de Impartición de Justicia Estatal 2018. SG. México. Extraído de: http://www3.inegi.org.mx/rnm/index.php/catalog/437 consulta: 24/03/2018.

Interno de 19 años (2018) Entrevista personal en el Penal de Chalco. Comunicación 22 de junio. Chalco, México.

Interno de 21 años (2018) Entrevista personal en el Penal de Chalco. Comunicación 14 de junio. Chalco, México.

Interno de 26 años (2018) Entrevista personal en el Penal de Chalco. Comunicación 11 de junio. México.

Lefebvre Henri. (1973) El derecho a la ciudad. Península, Argentina

Méndez López Rafael (2019) Por cada 10 "ninis" solo uno vive en zona con alta incidencia criminal. Extraído de Milenio Diario. Extraído de: https://www.diariocambio.com.mx/2019/nacional/item/12862-por-cada-10-ninis-solouno-vive-en-zona-con-alta-incidencia-criminal consulta: 21/04/2019.

Redim. (2019) Informe de niñas y niños asesinados en la guerra contra el crimen organizado. Red por los Derechos de la Infancia en México. México. Extraído de: https://noticieros.televisa.com/historia/asesinaron-285-ninos-primer-trimestre-2019/ consulta: 15/06/2019

SESNSP. (2019) Incidencia Delictiva Nacional. SEGOB. México. Extraído de: https://www.gob.mx/sesnsp/articulos/incidencia-delictiva?idiom=es $\quad$ consulta: 03/06/2019.

Teresa (2018a) Entrevista personal, 6 de abril. Chalco. México.

Teresa (2018b) Entrevista personal,14 de abril. Chalco. México.

Teresa (2018c) Entrevista personal, 20 de abril. Chalco. México.

Vanguardia (2012) La Familia tiene el control de la policía, Extraído de Vanguardia, México Grupo de Diarios de América (GDA), extraído de: https://vanguardia.com.mx/edomexlafamiliatieneelcontroldelapolicia-1409243.html consulta: 02/11/2012. 